\title{
Article \\ Genetic Counseling and Management: The First Study to Report NIPT Findings in a Romanian Population
}

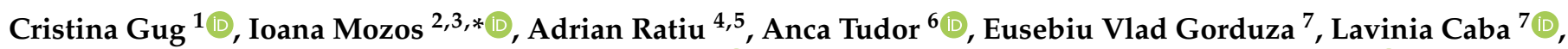 \\ Miruna Gug ${ }^{8}$, Catalina Cojocariu ${ }^{8}$, Cristian Furau ${ }^{9}{ }^{(1)}$, Gheorghe Furau ${ }^{10}$, Monica Adriana Vaida ${ }^{11}(\mathbb{D}$ \\ and Dorina Stoicanescu ${ }^{1}$
}

check for updates

Citation: Gug, C.; Mozos, I.; Ratiu, A.; Tudor, A.; Gorduza, E.V.; Caba, L.; Gug, M.; Cojocariu, C.; Furau, C.; Furau, G.; et al. Genetic Counseling and Management: The First Study to Report NIPT Findings in a Romanian Population. Medicina 2022, 58, 79. https://doi.org/10.3390/ medicina58010079

Academic Editor: Simone Ferrero

Received: 27 November 2021 Accepted: 30 December 2021 Published: 5 January 2022

Publisher's Note: MDPI stays neutral with regard to jurisdictional claims in published maps and institutional affiliations.

Copyright: (C) 2022 by the authors. Licensee MDPI, Basel, Switzerland. This article is an open access article distributed under the terms and conditions of the Creative Commons Attribution (CC BY) license (https:// creativecommons.org/licenses/by/ $4.0 /)$.
1 Department of Microscopic Morphology, "Victor Babeş" University of Medicine and Pharmacy, 300041 Timisoara, Romania; dr.cristina.gug@gmail.com (C.G.); dstoicanescu@gmail.com (D.S.)

2 Department of Functional Sciences, Discipline of Pathophysiology, "Victor Babes" University of Medicine and Pharmacy, 300173 Timisoara, Romania

3 Center for Translational Research and Systems Medicine, "Victor Babes" University of Medicine and Pharmacy, 300173 Timisoara, Romania

4 Department of Obstetrics and Gynecology II, "Victor Babes" University of Medicine and Pharmacy, 300041 Timisoara, Romania; dr.ratiu@gmail.com

5 Obstetrics-Gynecology Clinic IV, Municipal Emergency Clinical Hospital, 300231 Timisoara, Romania

6 Department of Functional Sciences, Discipline of Medical Informatics and Biostatistics, "Victor Babes" University of Medicine and Pharmacy, 300041 Timisoara, Romania; anca.ancutza@gmail.com

7 Department of Medical Genetics, Faculty of Medicine, "Grigore T. Popa” University of Medicine and Pharmacy, 700115 Iasi, Romania; vgord@mail.com (E.V.G.); lavinia_zanet@yahoo.com (L.C.)

8 Faculty of Medicine, "Victor Babeş" University of Medicine and Pharmacy, 300041 Timisoara, Romania; miruna.gug@gmail.com (M.G.); cati.cojocariu95@gmail.com (C.C.)

9 Life Sciences Department, Faculty of Medicine, "Vasile Goldis" Western University of Arad, 310414 Arad, Romania; cristianfurau@gmail.com

10 General Medicine Department, Faculty of Medicine, "Vasile Goldis" Western University of Arad, 310414 Arad, Romania; gfurau@yahoo.com

11 Department of Anatomy and Embryology, "Victor Babes" University of Medicine and Pharmacy, 300041 Timisoara, Romania; vaida.monica@umft.ro

* Correspondence: ioana_mozos@yahoo.com; Tel.: +40-745610004

Abstract: Background and Objectives: Non-invasive prenatal testing (NIPT) has been confirmed as the most accurate screening test for trisomies 21, 18, 13, sex chromosomes aneuploidies and several microdeletions. This study aimed to assess the accuracy of cell free DNA testing based on low-level whole-genome sequencing to screen for these chromosomal abnormalities and to evaluate the clinical performance of NIPT. Materials and Methods: 380 consecutive cases from a single genetic center, from Western Romania were included in this retrospective study. Cell-free nucleic acid extraction from maternal blood, DNA sequencing and analysis of sequenced regions were performed by BGI Hong Kong and Invitae USA to determine the risk of specific fetal chromosomal abnormalities. In high-risk cases the results were checked by direct analysis of fetal cells obtained by invasive methods: 6 chorionic villus sampling and 10 amniocenteses followed by combinations of QF-PCR, karyotyping and aCGH. Results: NIPT results indicated low risk in $95.76 \%$ of cases and high risk in $4.23 \%$. Seven aneuploidies and one microdeletion were confirmed, the other results were found to be a false-positive. A gestational age of up to 22 weeks had no influence on fetal fraction. There were no significant differences in fetal fraction across the high and low risk groups. Conclusions: This is the first study in Romania to report the NIPT results. The confirmation rate was higher for autosomal aneuploidies compared to sex chromosome aneuploidies and microdeletions. All cases at risk for trisomy 21 were confirmed. Only one large fetal microdeletion detected by NIPT has been confirmed. False positive NIPT results, not confirmed by invasive methods, led to the decision to continue the pregnancy. The main limitation of the study is the small number of patients included. NIPT can be used as a screening method for all pregnancies, but in high-risk cases, an invasive confirmation test was performed. 
Keywords: prenatal diagnostics; prenatal screening; next-generation sequencing; non-invasive prenatal testing

\section{Introduction}

Non-invasive prenatal testing (NIPT) has been increasingly used in the last decade, initially for the screening of common fetal aneuploidies and then of several structural chromosomal abnormalities [1-3]. Conventional aneuploidy screening technology was introduced in 2011. The discovery of cell-free fetal DNA in the plasma of pregnant women by Lo et al. in 1997 [4] provided the opportunity for NIPT. The introduction and rapid progress of next generation sequencing (NGS) technologies have increased the accuracy of the method [5]. Several studies reported a combined specificity for aneuploidies of $99.9 \%$, much more accurate than biochemical screening [6-10]. Sonography and maternal biochemistry prenatal screening of fetal aneuploidies have a detection rate within 50-95\% [5].

Sex chromosome aneuploidies that can also be identified using NIPT have a lower detection rate, especially monosomy $\mathrm{X}$, with a higher false positive rate compared to autosomal trisomies. The average positive predictive value (PPV) for sex chromosome anomalies screening was estimated at $40.56 \%$ [5,11]. NIPT has several limitations regarding the detection of more rare fetal chromosomal abnormalities, other than aneuploidy for $3(13,18,21)$ or 6 pairs $(13,18,21,9,16,22)$ of autosomal chromosomes, or the identification of cases with mosaicism.

Segmental duplications or deletions, also called copy number variations (CNVs), are extensively distributed in the human genome and many are associated with diseases [12-17]. The incidence of microdeletions/microduplications is independent of maternal age [18]. Structural chromosome abnormalities also remain difficult to detect. An algorithm known as Fetal Copy Number Analysis through Maternal Plasma Sequencing was developed to detect, close to $100 \%$, deletions/duplications $\geq 10 \mathrm{Mb}$ [19].

NIPT is widely used today, it is especially applied for the screening of autosomal trisomies, with the advantage of not requiring invasive sampling and having high accuracy, sensitivity and specificity [20]. Based on multiple meta-analyses, false positive rates range between $0.04 \%$ and $0.06 \%$ for the autosomal trisomies 21,18 and 13 . The detection rate of sex chromosome aneuploidies varies, being $90.3 \%$ for monosomy $\mathrm{X}$ with a $0.23 \%$ false positive rate. The detection rate for sex chromosome trisomies was $93.0 \%$, and the false positive rate was $0.14 \%$ [21]. Invasive diagnostic tests such as amniocentesis or chorionic villus sampling remain the gold standard for the accurate diagnosis of chromosomal abnormalities.

In the present study, we aimed to assess the accuracy of cell free DNA (cfDNA) testing based on low-level whole-genome sequencing to screen for common aneuploidies and some microdeletions and evaluated the clinical performance of NIPT using maternal plasma cfDNA.

\section{Materials and Methods}

\subsection{Patients and Sample Collection}

A retrospective study was conducted including data obtained from a single private genetic center that collects cases from the western part of Romania. From September 2014 to September 2020, the NIPT was performed in 380 Caucasian pregnant women, including 4 twin pregnancies and 7 pregnancies obtained by in vitro fertilization (IVF). Exclusion criteria were as follows: more than two fetuses, pregnancy after stem cell therapy or organ transplantation, invasive cancers. All pregnancies were assessed by the obstetriciangynecologists before maternal blood sampling. All subjects had a pretest ultrasound scan to determine the gestational age and number of fetuses.

The study was conducted in accordance with the Declaration of Helsinki. Ethical approval was provided by the Human Research Ethics Committee from the Emergency 
Clinical Municipal Hospital Timisoara, Romania (No. 6-2846 from 8 July 2020). Written informed consent was obtained from all investigated women to perform NIPT and to publish the results in the future.

Two types of tests, NIFTY (Non-Invasive Fetal Trisomy) in 225 cases and NIPS (noninvasive prenatal screening) in 155 cases were used. The samples were processed in Hong Kong and the USA, respectively. The NIFTY test was the first NIPT available in Romania. To our knowledge, NIPS has a very good accuracy-cost ratio (in our country NIPT is not covered by health insurance).

\subsection{Genetic Counseling}

Genetic counseling was provided two or three times to each couple. Maternal age, gestational age, biochemical or ultrasound markers results, obstetric history, and the existence of genetic diseases in the family were recorded during pretesting counseling, and the pedigree analysis was performed. The second genetic counseling was performed after the genetic screening using NIPT. The future parents were informed about the result of the test, which showed a low or high-risk of chromosomal abnormalities. In all high-risk cases, we recommended and performed a genetic diagnosis using an invasive method, chorionic villus sampling (CVS), or amniocentesis, followed by a combination of tests: Quantitative Fluorescent Polymerase Chain Reaction (QF-PCR), array Comparative Genomic Hybridization $(\mathrm{aCGH})$ and karyotyping. After obtaining the result, a third genetic counseling session was performed, in order to explain the significance of the obtained results.

\subsection{NIPT: NIFTY and NIPS Tests}

The NIFTY test (BGI Laboratory) enables the isolation of cfDNA (including both maternal and fetal DNA) from a maternal blood sample and performs low coverage whole genome sequencing using NGS technology. The unique reads for each chromosome are calculated and compared to an optimal reference control sample. Data is analyzed using a BGI's bioinformatics algorithm, and a risk score is generated for the tested conditions. For gender identification, cfDNA isolation is necessary (including both maternal and fetal DNA) from a maternal blood sample, followed by molecular genetic testing.

The NIFTY test enables the identification of 6 autosomal aneuploidies (chromosomes $13,18,21,9,16$, and 22), sex chromosomes aneuploidies and 84 microdeletion syndromes. The test was validated for deletion/duplication (del/dup) syndromes larger than $10 \mathrm{Mb}$. The detection rate is over $90 \%$ if the size of the deletion/duplication is $3 \mathrm{Mb}$, according to the specifications of the BGI Laboratory. The NIFTY test was used during 2014-2020 in 225 cases.

The other test we used was NIPS, which allows the identification of pregnancies at risk for aneuploidies of chromosomes 13, 18, 21, and for 6 microdeletion syndromes: $1 \mathrm{p} 36$ deletion syndrome, 4p16.3 (Wolf syndrome), 5p15.2 (Lejeune syndrome), 15q11.2 (Prader-Willi and Angelman syndromes) and del (22q11.2) in singleton pregnancies. Invitae laboratory uses cfDNA extraction from maternal blood, DNA sequencing and analysis of sequenced regions to determine the risk of the above mentioned fetal chromosomal abnormalities. Other mechanisms that cause Prader-Willi and Angelman syndromes, such as uniparental disomy, have not been examined. The NIPS test was used during 2019-2020 on 155 cases. A percentage of $Y$ chromosome $\geq 0.0048$ and $<0.0048$ is considered as a male and a female fetus, respectively. The accuracy is at least $97 \%$.

The NIPT is validated to detect fetal chromosome trisomy 21, 18, and 13 and the presence of the $\mathrm{Y}$ chromosome for twin pregnancies at a minimum gestational age of 10 weeks 0 days. Both tests can reveal fetal sex and sex chromosomes aneuploidies.

\subsection{Cell Culture}

An invasive method for fetal cell sampling (CVS or amniocentesis) was performed in every case with positive NIPT results. The invasive diagnostic procedures were performed by the obstetricians. All cytogenetic analyses were performed in our laboratory. Amniotic 
or chorionic villus cell cultures were initiated in 2 different flasks with AmnioMAXTM-II complete medium (Gibco-Thermo Fisher, Waltham, MA, USA) containing fetal bovine serum, gentamicin and L-glutamine. On the fifth day of cell culture, the growth medium was changed, and subsequently, cell growth and number of mitoses were monitored daily. Long-term cultures were performed (12 days), and the cells were then harvested by routine techniques.

\subsection{Cytogenetics}

At least 20 metaphases per each sample were analyzed using GTG banding (at the 550-band level). Results were regularly available within 14-18 days. Analysis of the chromosomes was performed using LUCIA Karyo G software, and the aberrations and karyotypes were classified according to the International System for Human Cytogenomic Nomenclature 2016 [ISCN, 2016].

\subsection{QF-PCR Assay}

If a high-risk of aneuploidy for chromosomes 13, 18, 21, X, and $\mathrm{Y}$ was detected by NIPT/NIPS, the samples were verified by the rapid QF-PCR assay. IVD QF-PCR Devyser (Devyser AB, Stockholm, Sweden) and Elucigene (Tepnel Diagnostics, Manchester, England) kits were used. Promega Wizard ${ }^{\mathrm{TM}}$ Genomic (Promega, Madison, WI, USA) kit was used for DNA purification. Commercially available kits were used for the quantitative PCR reaction and ABI3730xl platform (Applied Biosystems, Waltham, MA, USA) was used for the amplicons migration. QF-PCR tests were performed by a partner laboratory (CytoGenomic Medical Laboratory, Bucharest, Romania).

\subsection{Array CGH}

Array CGH was performed using Cyto Chip Focus Constitutional BAC array (Illumina Inc., San Diego, CA, USA), and the used reference was the normal human male genomic DNA (Promega Corporation, Madison, WI, USA). Array CGH analyses were also performed by CytoGenomic Medical Laboratory.

\subsection{Data Analysis}

For a statistical presentation, the results were reconsidered after classifying pregnancies according to maternal age ( $<34$ years and $\geq 35$ years).

Statistical processing was performed using SPSSv17 (version 17, SPSS Inc., Chicago, IL, USA) and Microsoft Excel (version 2013, MS Corp., Redmond, WA, USA). In the case of nominal variables, the frequency tables were prepared together with the "pie" type graphs and the associations between these types of variables were performed with the Chi ${ }^{2}$ test; also, for some of these variables we made Risk Analysis (Odds ratio calculated with the $95 \%$ confidence interval for OR). For the numerical variables, the descriptive statistics were calculated, and histograms and column graphs were made. Comparisons between numerical series were performed with nonparametric tests because our continuous variables had non-Gaussian distribution; in case of comparisons between two series of values we applied the Mann-Whitney $U$ test in case of comparisons between two series of values with non-Gaussian distribution and with Kruskal-Wallis test for comparisons between more than two series. The correlations between two numerical series were made with Spearman's correlation analysis. We used the value of $p<0.05$ for significant differences.

We calculated positive predictive value (PPV) and negative predictive value (NPV) both for aneuploidies and microdeletions, as we had confirmed cases, but also false positive results. PPV is defined as the probability that a positive result will be true and NPV is the probability that a negative result will be true. Public databases (OMIM, DECIPHER, NCBI, ClinVar) were used to interpret the data. 


\section{Results}

\subsection{Distribution of Cases by Years, Depending on the Identified Anomalies}

From September 2014 to September 2020, NIPT was performed in 380 pregnant women in a private genetic center from Timisoara, Romania. There were 380 cfDNA maternal plasma samples and 378 of them were successful (99.47\%). In two cases, the analysis could not be performed even after a second blood sample was taken. Seven pregnancies resulting from IVF were included. A low risk was identified in $95.76 \%(362 / 378)$ of cases that were considered normal pregnancies and were further monitored. A high risk of aneuploidy has been identified in $2.64 \%$ (10/378) of cases. Increased risk for microdeletion syndromes has been identified in 1.05\% (4/378) of cases. Combined anomalies risk (one aneuploidy and one microdeletion) has been identified in $0.52 \%(2 / 378)$ of cases. The number of investigations increased from 2014 to 2020, which shows the growing interest in this type of testing for pregnant women in Romania. Figure 1 shows the distribution of cases and anomalies identified throughout the studied period.

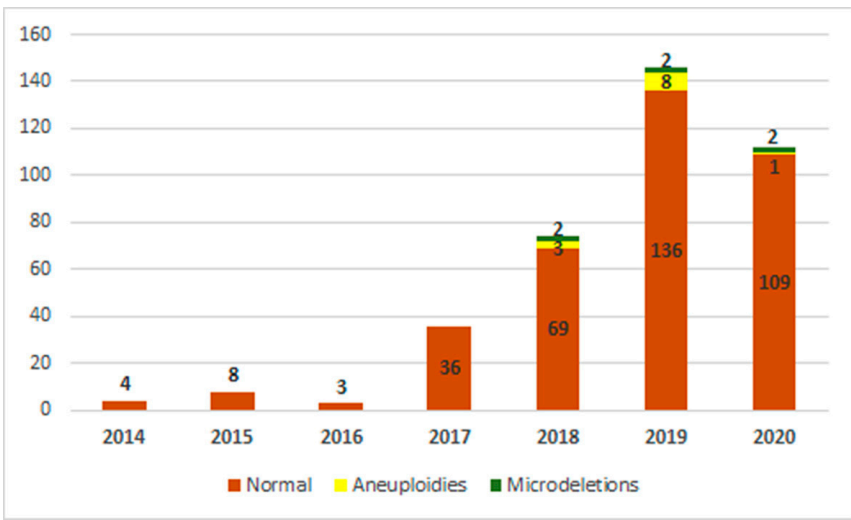

Figure 1. Distribution of cases over time, specifying the type and number of detected abnormalities (aneuploidies and microdeletions).

\subsection{Analysis Duration for the NIPT}

Given that the tests were performed in Hong Kong or in the USA, and that blood samples had to be sent by international transport, part of the time was "lost". However, the average duration of the analysis was 7 days, ranging from 4 to 10 days.

\subsection{Gestational Age at the Time of NIPT}

The mean gestational age was $12.62 \pm 2.47$ weeks (range: 10-22 weeks) (Figure 2a). Most cases (55 cases) had a gestational age of 10 weeks.

\subsection{Fetal Fraction}

NIPT is based on the percentage (\%) of cell-free DNA in the mother's blood, also called fetal fraction (FF). In our study, these percentages were highly variable, with a mean of $10.96 \% \pm 4.14$, ranging between $3.5 \%$ and $28.12 \%$ (Figure $2 b$ ).

In 4 cases the analysis failed initially, but it was successful in 2 of them after a second blood sample was taken, hence finally, 378 cases received a NIPT risk result. FFs in these 2 cases were $8.58 \%$ and $10.96 \%$, respectively. As FF values were within such a wide range, we evaluated the relationships between FF and different parameters to find significant associations (Table 1). 


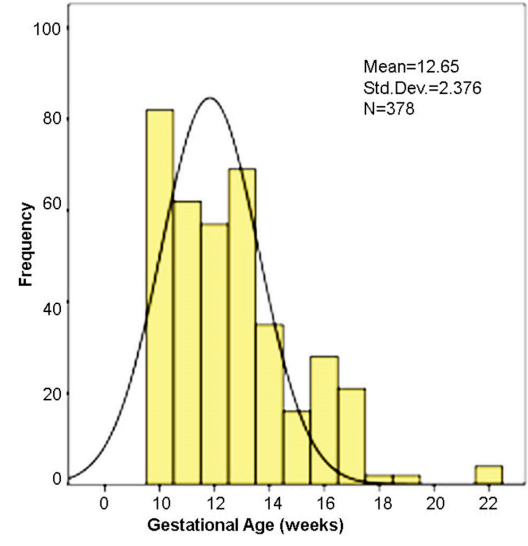

(a)

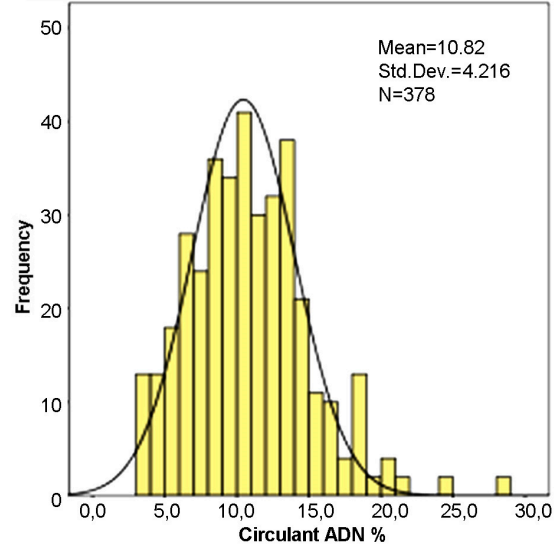

(b)

Figure 2. (a) Distribution of gestational age values. (b) Distribution of cell-free DNA percentage in maternal blood.

Table 1. Fetal fraction descriptive statistics for different parameters.

\begin{tabular}{|c|c|c|c|c|c|}
\hline Parameters & Result & $\begin{array}{l}\text { Number } \\
\text { of Cases }\end{array}$ & Mean FF ${ }^{1}$ & $\mathrm{SD}^{2}$ & $\begin{array}{l}\text { Standard Error } \\
\text { of the Mean }\end{array}$ \\
\hline \multirow{2}{*}{ Maternal age } & Up to 34 years & 215 & 11.23 & 4.28 & 0.37 \\
\hline & Over 35 years & 163 & 10.61 & 3.93 & 0.39 \\
\hline \multirow[b]{2}{*}{$\begin{array}{l}\text { NIPT risk of } \\
\text { aneuploidy }\end{array}$} & No risk & 362 & 11.03 & 4.14 & 0.28 \\
\hline & $\begin{array}{c}\text { Risk for aneuploidy } \\
\text { as a unique } \\
\text { abnormality }\end{array}$ & 10 & 10.40 & 4.18 & 0.82 \\
\hline \multirow{3}{*}{$\begin{array}{l}\text { NIPT risk of } \\
\text { aneuploidy } \\
\text { NIPT risk of } \\
\text { microdeletion }\end{array}$} & $\begin{array}{l}\text { Risk for aneuploidy } \\
\text { and microdeletion }\end{array}$ & 2 & 10.21 & 4.07 & 0.54 \\
\hline & No risk & 372 & 10.93 & 4.16 & 0.27 \\
\hline & $\begin{array}{c}\text { Risk for } \\
\text { microdeletion as a } \\
\text { unique abnormality }\end{array}$ & 4 & 12.57 & 2.76 & 1.23 \\
\hline \multirow{3}{*}{$\begin{array}{l}\text { NIPT risk of } \\
\text { microdeletion } \\
\text { Risk } \\
\text { confirmation }\end{array}$} & $\begin{array}{l}\text { Risk for } \\
\text { microdeletion and } \\
\text { aneuploidy }\end{array}$ & 2 & 11.03 & 3.07 & 0.89 \\
\hline & Not necessary & 362 & 11.00 & 4.22 & 0.28 \\
\hline & Not confirmed & 7 & 9.17 & 2.40 & 0.98 \\
\hline \multirow{2}{*}{$\begin{array}{c}\text { Risk } \\
\text { confirmation }\end{array}$} & Confirmed & 9 & 11.24 & 2.61 & 0.87 \\
\hline & Total & 378 & 10.96 & 4.14 & 0.27 \\
\hline
\end{tabular}

$\mathrm{FF}^{1}$, Fetal fraction (\%); $\mathrm{SD}^{2}$, standard deviation; $\mathrm{NIPT}^{3}$, non-invasive prenatal test.

A gestational age of up to 22 weeks had no influence on fetal fraction. We did not find significant differences in fetal fraction across the high and low-risk groups.

The results of the associations between FF and different parameters were not statistically significant (Table 2).

\subsection{Sex of the Fetus}

The identification of the $\mathrm{Y}$ chromosome indicated the male fetal sex. Fetal sex was female in $52.64 \%(199 / 378)$ of cases and male in $47.35 \%(179 / 378)$, with a sex ratio $=\mathrm{M} / \mathrm{F}$ of 0.899 . As the $X$ and $Y$ chromosomes can be identified, by default, sex chromosome aneuploidies can be identified as well. In this study group no such syndromes were identified, although two results indicated a high-risk of $X$ monosomy, but this aneuploidy was not subsequently confirmed by the invasive method. 
Table 2. Associations between fetal fraction and different parameters.

\begin{tabular}{|c|c|c|}
\hline Parameters Associated with FF ${ }^{1}$ & Statistical Significance & Statistical Analysis/ $p$ Values \\
\hline Gestational age & no significant correlation & $\begin{array}{l}\text { Spearman Correlation } \\
\rho=0.053 / p=0.418\end{array}$ \\
\hline $\begin{array}{l}\text { Pregnant women in the age risk } \\
\text { category, over } 35 \text { years }\end{array}$ & insignificantly lower & $\begin{array}{l}\text { Mann-Whitney } \\
\mathrm{U} \text { test } / p=0.400\end{array}$ \\
\hline Maternal age & no significant correlation & $\begin{array}{l}\text { Spearman Correlation } \\
\rho=-0.022 / p=0.740\end{array}$ \\
\hline $\begin{array}{l}\text { Pregnant women who had the } \\
\text { NIPT normal result }\end{array}$ & insignificantly increased & $\begin{array}{l}\text { Mann-Whitney } \\
\mathrm{U} \text { test } / p=0.728\end{array}$ \\
\hline $\begin{array}{l}\text { Pregnant women with no risk of } \\
\text { aneuploidy }\end{array}$ & insignificantly increased & Kruskal-Wallis test $/ p=0.315$ \\
\hline $\begin{array}{l}\text { Pregnant women at risk of } \\
\text { microdeletion as a single } \\
\text { abnormality }\end{array}$ & insignificantly increased & Kruskal-Wallis test $/ p=0.176$ \\
\hline $\begin{array}{l}\text { Cases confirmed by invasive } \\
\text { methods }\end{array}$ & insignificant association & Kruskal-Wallis test $/ p=0.490$ \\
\hline
\end{tabular}

$\mathrm{FF}^{1}$, Fetal fraction (\%).

\subsection{Maternal Age}

The mean maternal age in the entire group was $33.4 \pm 4.96$ years, ranging between 21 and 47 years. The patients were divided into two groups: under 34 years old and 35 years or older. We also calculated the mean age of pregnant women who were at risk for aneuploidy depending on the type of aneuploidy (Table 3).

Table 3. Mean maternal age in different groups.

\begin{tabular}{cccc}
\hline Maternal Age (Years) & Mean \pm SD $^{\mathbf{1}}$ & Minimum-Maximum & $\begin{array}{c}\text { Number } \\
\text { of Cases }\end{array}$ \\
\hline Group up to 34 years & $29.8 \pm 2.87$ & $21-34$ & 216 \\
Group over 35 years & $38.2 \pm 2.61$ & $35-47$ & 164 \\
Cases with NIPT risk for trisomy 21 & $34.8 \pm 6.38$ & $25-42$ & 5 \\
Cases with NIPT risk for trisomy 18 & $36.3 \pm 7.10$ & $30-44$ & 3 \\
Cases with NIPT risk for trisomy 13 & 39 & 39 & 1 \\
Cases with NIPT risk for trisomy 14 & 41 & 41 & 1 \\
Cases with NIPT risk for X & $33.5 \pm 4.95$ & $30-37$ & 2 \\
monosomy & & $25-44$ & 12 \\
Group with NIPT risk for all types of & $35.83 \pm 5.57$ & $25-42$ & 8 \\
tested aneuploidy & $34.5 \pm 5.21$ & $26-41$ & 6 \\
Group with confirmed aneuploidy & $35.5 \pm 6.09$ & 41 & 1 \\
Group with NIPT risk of aneuploidy & 41 & $21-47$ & 380 \\
and microdeletion & $33.4 \pm 4.96$ & & \\
Group with confirmed microdeletion & & & \\
Entire group & & &
\end{tabular}

$\mathrm{SD}^{1}$, standard deviation.

The association between advanced maternal age risk (age $>35$ years) and the aneuploidy risk was not statistically significant (chi-square test, $p=0.824$ ). Age over 35 years was not a significant risk factor for the occurrence of aneuploidy $(\mathrm{OR}=1.18, \mathrm{cu} 95 \% \mathrm{CI}=[0.5$, 2.78]), $p=0.824$ (Chi2 Test). Most cases were in the 30-34 age group, followed by the 35-39 age group (Figure 3 ). 


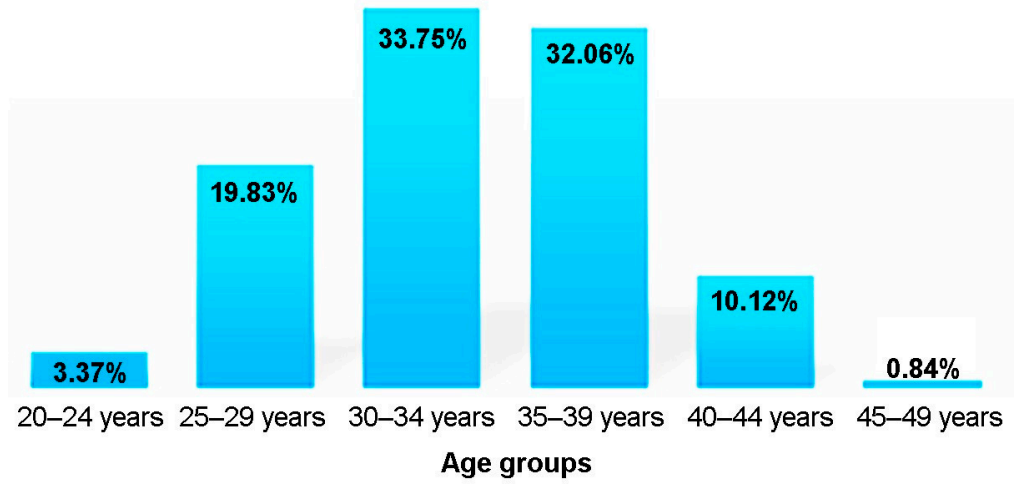

Figure 3. Distribution of cases considering maternal age.

\subsection{The Main Indications for the NIPT}

The indications for non-invasive prenatal testing were established for all 380 patients during the pre-testing genetic counseling (Figure 4). Most of the tests were performed at the gynecologist's indication for supervision of normal pregnancy, followed by the cases with advanced maternal age and positive obstetric history. Of the 8 cases with aneuploidy confirmed by invasive tests, 2 cases were in the age group under 34 years: maternal age was 25 years and trisomy 21 was confirmed in one case; another 30-year-old patient with twin pregnancy had a female twin with trisomy 18 . There were also cases with biochemical risk at the double test (DT), prenatal ultrasound abnormalities or with a balanced chromosomal abnormality. A total of $3.8 \%$ of cases had a positive family history for single-gene diseases; in these latter cases, the test was performed to identify the sex of the fetus.

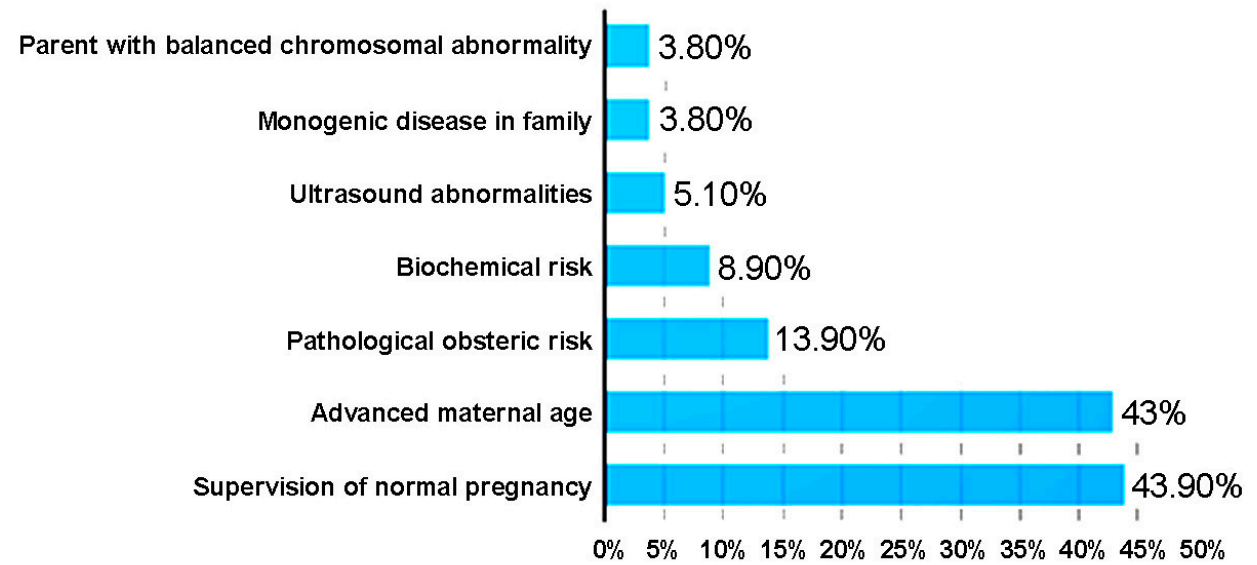

Figure 4. Indications for the NIPT.

Ultrasound abnormalities were identified in 19 fetuses (5\%), including 5 cases with increased fetal nuchal translucency (NT) $(\geq 3 \mathrm{~mm})$. The following abnormalities were recorded: intrauterine growth retardation, cardiac anomalies (tricuspid valve regurgitation, tetralogy of Fallot; aortic override, pulmonary artery stenosis, atrial septal defect), renal abnormalities (renal pyelectasis, bilateral hyperechogenic kidney), hyperechogenic fetal bowel, abnormal anterior abdominal wall, central nervous system abnormalities (bananashaped cerebellum with risk of neural tube defect, choroid plexus cysts of $5 \mathrm{~mm}$ ), abnormal venous duct with absent, bilateral hydrothorax, ascites, cystic hygroma, sexual ambiguity, polydactyly, clinodactyly. Combinations of indications for testing were registered in 12 cases $(3.15 \%)$, one of them having 3 and another one having 4 indications (Supplementary Material: Table S1).

Four pregnant women (1.05\%), carriers of an X-linked recessive gene, were offered the analysis for fetal sex determination. In all cases, there was a female fetus and the NIPT result was normal. 
In 10 cases $(2.63 \%)$, there was an indication related to the existence of a chromosomal disease in the family. In 6 cases there was a relative with trisomy 21 . In 3 cases other chromosomal abnormalities were identified: maternal translocation, paternal inversion and a de novo duplication of a previous child.

\subsection{The NIPT Results}

Of the 378 cases, 362 (95.76\%) had a low-risk, and 16 (4.24\%) had a high-risk. Of these, 8 cases $(2.12 \%)$ were confirmed by invasive methods, and $8(2.12 \%)$ were false-positive.

Correlations between the risk assessed by NIPT and the results of invasive prenatal diagnosis have also been performed (Table 4).

Table 4. The correlation between the risk assessed by NIPT and the final result.

\begin{tabular}{|c|c|c|c|c|c|c|}
\hline \multirow{2}{*}{ NIPT Risk Assessment } & \multirow{2}{*}{ Number of Cases } & \multirow{2}{*}{$(\%)$} & \multicolumn{3}{|c|}{ Invasive Prenatal Diagnosis } & \multirow{2}{*}{$\begin{aligned} & \text { PPV }^{1} \\
&(\%)\end{aligned}$} \\
\hline & & & Confirmed & False Positive & False Negative & \\
\hline $\begin{array}{c}\text { Total number of cases with } \\
\text { NIPT result }\end{array}$ & 378 & 100 & & & & \\
\hline NIPT low risk & 362 & 95.76 & - & - & - & 100 \\
\hline NIPT increased risk & 16 & 4.23 & 8 & & & \\
\hline $\begin{array}{l}\text { NIPT increased risk for } \\
\text { isolated aneuploidies }\end{array}$ & 10 & 2.64 & 7 & 3 & - & 70 \\
\hline Trisomy 21 & 5 & 1.32 & 5 & 0 & 0 & 100 \\
\hline Trisomy 18 & 3 & 0.79 & 2 & 1 & 0 & 66.66 \\
\hline Trisomy 13 & & 0 & 0 & 0 & 1 & 0 \\
\hline Monosomy X & 2 & 0.53 & 0 & 2 & 0 & 0 \\
\hline $\begin{array}{l}\text { NIPT increased risk for } \\
\text { aneuploidy and } \\
\text { microdeletion }\end{array}$ & 2 & 0.53 & 1 & 1 & 0 & 16.66 \\
\hline $\begin{array}{l}\text { Trisomy } 13 \text { and } 1 \text { p36 } \\
\text { microdeletion syndrome }\end{array}$ & 1 & 0.26 & $\begin{array}{l}0 \\
0\end{array}$ & $\begin{array}{l}1 \\
1\end{array}$ & 0 & 0 \\
\hline $\begin{array}{c}\text { Trisomy } 14 \text { and } \\
\operatorname{del}(\mathrm{X})(\mathrm{p} 22.33-11.21)\end{array}$ & 1 & 0.26 & $\begin{array}{l}0 \\
1\end{array}$ & $\begin{array}{l}1 \\
0\end{array}$ & 0 & 0 \\
\hline $\begin{array}{l}\text { NIPT increased risk for } \\
\text { isolated microdeletions }\end{array}$ & 4 & 1.04 & 0 & 4 & 0 & 0 \\
\hline $\operatorname{del}(10 q 25.2-q 26.3)$ & 1 & 0.26 & 0 & 1 & 0 & 0 \\
\hline $\operatorname{del}(15)(q 11.2-13.1)$ & 1 & 0.26 & 0 & 1 & 0 & 0 \\
\hline del(20q11.21-q13.13) & 1 & 0.26 & 0 & 1 & 0 & 0 \\
\hline $\begin{array}{l}\operatorname{del}(22 q 11.2) \text { microdeletion } \\
\text { syndrome }\end{array}$ & 1 & 0.26 & 0 & 1 & 0 & 0 \\
\hline
\end{tabular}

$\mathrm{PPV}^{1}$, Positive predictive value.

In one case, the NIPT result suggested a large chromosomal deletion that was confirmed by aCGH, but with increased size, $61.88 \mathrm{Mb}$, compared to the size of $54.27 \mathrm{Mb}$ determined by the NIPT. In this case, FF was $15.64 \%$, the highest in the group at risk of microdeletions. The rest of the cases found to be at risk of microdeletions were not confirmed by direct methods (aCGH) (Table 5).

\subsection{Invasive Methods for Verifying (Confirmation/Exclusion) NIPT Results}

Direct analysis of fetal cells obtained by invasive methods was performed to verify the 16 cases identified to be at risk. Six CVS and ten amniocenteses were performed, followed by combinations of QF-PCR, karyotyping and aCGH. Thus, 29 analyzes were performed, of which 12 were QF-PCR, 11 karyotypes and 6 microarrays. One of the twin pregnancies benefited from 2 karyotypes and the other from 2 QF-PCR analyzes and 2 karyotypes. 
Table 5. Description of cases at risk for microdeletions.

\begin{tabular}{|c|c|c|c|c|}
\hline $\begin{array}{l}\text { NIPT High Risk for } \\
\text { Microdeletions }\end{array}$ & $\begin{array}{c}\text { Size }\left(\mathrm{Mb}^{\mathbf{1}}\right) \\
\text { Determined by } \\
\text { NIPT }\end{array}$ & $\begin{array}{l}\text { FF }^{2} \\
(\%)\end{array}$ & $\begin{array}{c}\text { Gestational Age } \\
\text { (Weeks) }\end{array}$ & $\begin{array}{c}\mathrm{aCGH}^{3} \\
\text { and Size }(\mathrm{Mb})\end{array}$ \\
\hline $\operatorname{del}(X)(p 22.33-11.21)$ & 54.27 & 15.64 & 13 & $\begin{array}{c}\operatorname{arr}[\text { GRCh37] } \\
\text { Xp22.33p11.1 } \\
\left(168551 \_62051248\right) \times 1 \\
\text { 61.88 Mb }\end{array}$ \\
\hline del(10q25.2-q26.3) & 22.57 & 5.3 & 11 & False-positive \\
\hline $\operatorname{del}(20 q 11.21-q 13.13)$ & 18.40 & 8.32 & 12 & False-positive \\
\hline $\begin{array}{c}\operatorname{del}(15)(q 11.2-13.1) \\
\operatorname{del}(22 q 11.2)\end{array}$ & 5.60 & 10.96 & 13 & False-positive \\
\hline $\begin{array}{l}\text { microdeletion } \\
\text { syndrome }\end{array}$ & 2.54 & 9 & 12 & False-positive \\
\hline $\begin{array}{c}\text { 1p36 microdeletion } \\
\text { syndrome }\end{array}$ & 2.30 & 12.3 & 16 & False-positive \\
\hline
\end{tabular}

$\mathrm{Mb}^{1}$, Megabase; $\mathrm{FF}^{2}$, fetal fraction; aCGH ${ }^{3}$, Array CGH.

In all cases at risk of aneuploidies, 12 fetal karyotypes and 10 QF-PCR analyzes were performed, the latter in order to obtain rapid results. The cases at risk of $X$ monosomy and trisomy 14 were not confirmed.

Two cases at risk of aneuploidy, one with trisomy 21 and one with trisomy 18, were from twin pregnancies. Two amniocenteses were performed separately for each fetus, confirming trisomy 21 in the male fetus from one twin pregnancy and trisomy 18 in the female fetus from the other twin pregnancy.

Two cases were at risk for both numerical and structural abnormalities, and amniocentesis was required, followed by fetal karyotyping and microarray. One case $(0.26 \%)$ was at risk for trisomy 14, which has not been confirmed, in association with Xp microdeletion, which was confirmed, and the pregnancy was stopped for medical reasons. Another case had a high-risk for trisomy 13 and for microdeletion 1p36, but they were both ruled out and the pregnancy continued.

A high-risk of microdeletion syndromes as unique abnormalities was identified in 4 cases (1.04\%): del (10q25), del(15q), del(20q), and del(22q11.2). As mentioned, a high-risk for a microdeletion and an aneuploidy was identified in 2 cases: del(1p36) and trisomy 13 in one case and $\operatorname{del}(\mathrm{Xp})$ and trisomy 14 in the other one (Tables 4 and 5). In all these 6 cases aCGH was performed. The case at risk for a large deletion, of $61.88 \mathrm{Mb}$, $\operatorname{del}(\mathrm{X})(\mathrm{p} 22.33-11.21)$ was confirmed, but the other 5 cases proved to be a false-positive: del(10q25.2-q26.3), $\operatorname{del}(15)(\mathrm{q} 11.2-13.1)$, del(20q11.21-q13.13), and two microdeletion syndromes: $1 \mathrm{p} 36$ and $\operatorname{del}(22 q 11.2)$.

\subsection{Positive Predictive Value (PPV)}

Regarding the high-risk for aneuploidies, out of the 12 cases, 7 were confirmed; therefore, PPV was 58.33\%, while regarding the high-risk for microdeletions, out of the 6 cases, only one was confirmed, and PPV was 16.66. Of the 12 aneuploidies, 5 cases (including one from a twin pregnancy) had an increased risk for trisomy 21, and all were confirmed; therefore, we report 100\% PPV for trisomy 21. The other 3 cases (including one from a twin pregnancy) had an increased risk for trisomy 18, and two were confirmed; therefore, we report $66.66 \%$ PPV for trisomy 18 . One case had an increased risk for trisomy 13, but it was ruled out, and we reported $0 \%$ PPV for trisomy 13. A special case was one obtained by IVF with an increased risk for X monosomy. CVS with QF-PCR ruled out this diagnosis, but identified trisomy 13, and post-test ultrasound at week 12 showed specific congenital anomalies (polydactyly). This case was a false-negative for trisomy 13 and false-positive for monosomy $\mathrm{X}$. As it was the only case at high-risk for trisomy 13 in the entire group, the NPV was $100 \%$. The second case with increased risk only for $X$ monosomy has not been confirmed. Both cases at risk of $\mathrm{X}$ monosomy were false positive. 
A comparison of specificity, sensitivity, and PPV scores for aneuploidies is presented in Table 6.

Table 6. Comparison of specificity, sensitivity and ppv scores for aneuploidies between NIFTY and NIPS tests.

\begin{tabular}{|c|c|c|c|c|c|c|c|}
\hline \multirow[t]{2}{*}{$\begin{array}{l}\text { Chromosomal } \\
\text { Abnormality }\end{array}$} & \multicolumn{2}{|c|}{ Sensitivity } & \multicolumn{2}{|c|}{ Specificity } & \multicolumn{3}{|c|}{ PPV $^{1}$} \\
\hline & $\begin{array}{c}\text { NIFTY } \\
\text { BGI }\end{array}$ & $\begin{array}{c}\text { NIPS } \\
\text { INVITAE }\end{array}$ & $\begin{array}{c}\text { NIFTY } \\
\text { BGI }\end{array}$ & $\begin{array}{c}\text { NIPS } \\
\text { INVITAE }\end{array}$ & $\begin{array}{c}\text { NIFTY } \\
\text { BGI }\end{array}$ & $\begin{array}{c}\text { NIPS } \\
\text { INVITAE }\end{array}$ & $\begin{array}{c}\text { Present } \\
\text { study }\end{array}$ \\
\hline Trisomy 21 & $99.17 \%$ & $99.99 \%$ & $99.95 \%$ & $99.89 \%$ & $92.19 \%$ & 92.89 & $100 \%$ \\
\hline Trisomy 18 & $98.24 \%$ & $99.99 \%$ & $99.95 \%$ & $99.99 \%$ & $76.61 \%$ & 89.11 & $66.66 \%$ \\
\hline Trisomy 13 & $>99.9 \%$ & $99.99 \%$ & $99.96 \%$ & $99.69 \%$ & $32.84 \%$ & 73.54 & $0 \%$ \\
\hline Monosomy X & $>99.9 \%$ & $99.99 \%$ & - & $99.89 \%$ & $40 \%$ & 69.15 & $0 \%$ \\
\hline
\end{tabular}

$\mathrm{PPV}^{1}$, Positive predictive value.

\section{Discussion}

Until recently, prenatal screening for fetal aneuploidies relied on the measurement of maternal serum biochemical markers combined with fetal ultrasound markers [22]. At present, in Romania, NIPT is used as a commercial service in the clinical detection of common chromosomal aneuploidies and microdeletions. In Romania, in high-risk cases, invasive prenatal diagnosis became available in 2002 [23]. NIPT has become more widely accessible, giving women the opportunity to benefit from these services.

Non-invasive prenatal testing analyzing FF in maternal blood has rapidly developed in the last few years. It is used as a screening test for the most common chromosomal disorders. NIPT relies on the presence of fragments of cell-free placental and maternal DNA in maternal blood to assess the risk of an affected pregnancy. The test compares the total maternal and fetal DNA in a maternal blood sample to a control sample using advanced bioinformatics analysis. It is provided for screening only. False-negative and false-positive results may occur. This test assesses the risk for the following chromosomal abnormalities: trisomy 21, 18, 13, sex chromosome aneuploidies, and several microdeletions [19,24].

NIPT can be performed at any stage of the pregnancy, generally from 10 weeks' gestation onwards, to ensure adequate cfDNA in the maternal plasma sample [25-27]. In our study group, NIPT was performed between 10 and 22 weeks of pregnancy. However, most cases came immediately after 10 weeks of gestation, with a mean of $12.62 \pm 2.47$ weeks.

\subsection{Fetal Fraction}

The proportion of cfDNA molecules is expressed as the fetal DNA fraction in the plasma of pregnant women [21]. We analyzed the association between FF and the following parameters: gestational age, maternal age, and NIPT risk result for aneuploidies and for microdeletions, but no significant correlations were found.

In our study, a gestational age of up to 22 weeks had no influence on FF, consistent with the results of Hestand et al. [28]. Other studies found that the FF positively correlated with gestational age [29] and significantly increased especially beyond 23 weeks of gestation, but waiting for a late gestational age is not a reliable approach $[27,30]$.

We found lower FF values in pregnant women over 35 years compared to those under 35 years, but the difference was not statistically significant. Hou et al. [30] found that the percentage of FF significantly decreased with an increase in maternal age. A negative correlation between FF of cfDNA and maternal age was reported by Guo et al. [29], while Hestand et al. found no influence of maternal age on FF [28].

We did not find significantly increased FF values in pregnant women with low-risk NIPT results. In a study regarding FF in pregnancies with a low and high-risks for fetal chromosomal aneuploidies, Hudecova et al. reported no statistically significant difference in FF across the high, intermediate, and low-risk groups [31]. 
In our study, the FF values were not significantly increased in pregnant women at risk of a microdeletion. Using multivariate regression analysis to determine several maternal and fetal factors that might be significant predictors of the FF, Ashoor et al. found that fetal karyotype did not provide a significant independent prediction of FF [32]. Another study compared FF in euploid versus aneuploid pregnancies and found that the median FF was significantly higher in Down syndrome pregnancies and significantly lower in trisomy 18 and triploid pregnancies. Some results were not informative, and this was due to low FF, but the authors considered that the high-risk for trisomy 18 and/or triploidy warranted offering additional assessments [33]. NIPT could establish a risk in our study in 378 cases and the FF range was found between $3.5 \%$ and $28.12 \%$, with a mean of $10.96 \pm 4.14 \%$. It was confirmed that the important prerequisites for NIPT are FF $>3.5 \%$ and gestational age over 10 weeks of pregnancy. An FF-based risk model was built for pregnancies with a FF too low to receive a result on standard NIPT. This algorithm can identify a subset of cases at increased risk for trisomy 13, trisomy 18, or triploidy [34].

Invasive assays used in our cases were CVS and amniocentesis. The main advantage of CVS is that it can be performed immediately after obtaining the NIPT result; hence a result can be obtained in the shortest possible time. Patients who underwent amniocentesis could not have CVS because the pregnancies were advanced, close to week 16 .

\subsection{Maternal Age}

The mean maternal age in the group detected to be at high-risk for aneuploidies was 35.83 years (range between 25-44 years), but if we exclude the false-positive cases and consider only the confirmed aneuploidies, mean maternal age was 34.5 years (range between 25-42), very close to the mean age of the entire study group, which was 33.4 years (ranging between 21-47 years). The mean values were somewhat close, therefore not statistically significant, and considering the very wide ranges found in the study group, it did not help us in assessing the risk before NIPT was performed. This is one of the reasons why we advocate for performing the NIPT in all pregnancies, even in the absence of classical indications.

Pretest genetic counseling helps identify potential risks and often puts an order in the conflicting ideas of anxious pregnant women [35,36].

\subsection{Aneuploidies}

If a fetus has a trisomy, the fetal-derived DNA molecules from the extra chromosome should be increased in maternal plasma, when compared to a pregnancy with a euploid fetus $[37,38]$.

Trisomy 21 was the only abnormality for which the NIPT risk result was confirmed in full, PPV being 100\%. The mean maternal age in these cases was 34.8 years. According to BGI versus Invitae specifications for trisomy 21 , sensitivity is $99.17 \%$ versus $99.99 \%$, specificity is $99.95 \%$ versus $99.89 \%$, and PPV is $92.19 \%$ versus $92.89 \%$ (Table 6). Only $20 \%$ of our cases had ultrasound abnormalities, $40 \%$ had abnormal prenatal biochemical screening results-double test, and another $40 \%$ had maternal age over 35 years as the only indication for NIPT. Yamada et al. reported a lower maternal age-specific risk for trisomy 21 based on the clinical performance of NIPT compared to the risk predicted in several other studies [39].

NIPT was positive for trisomy 18 in 3, cases but only 2 have been confirmed, PPV being $66.66 \%$. Interestingly, the case with the false-positive result that was not confirmed by amniocentesis followed by QF-PCR was 44 years old. Much higher PPV values were available from both partner laboratories: 76.61\% (BGI) and 89.11\% (Invitae) (Table 6) [21,40,41].

One of our cases had a high-risk for trisomy 13 and for 1p36 microdeletion, both abnormalities being excluded after amniocentesis followed by QF-PCR and aCGH. The pregnant woman was 39 years old and gave birth to a healthy baby. In contrast, another 37-year-old woman with the pregnancy achieved by IVF, with cystic hygroma and heart abnormality on a prenatal ultrasound, and NIPT high-risk for monosomy $X$ was found to 
have a fetus with trisomy 13 after CVS with QF-PCR was performed [42]. Preimplantation genetic testing was not performed in this case. Post-NIPT ultrasound identified polydactyly, and the pregnancy was stopped for medical reasons. In a report on NIPT using fetal DNA from maternal plasma for trisomy 13 detection, Yu et al. found the sensitivity and specificity of $95.2 \%$ and $99 \%$, respectively [43].

NIPT identified an increased risk for monosomy $X$ in two cases, but both were falsepositive, PPV being $0 \%$ in our study group. Monosomy $X$ has the lowest PPV, $40 \%$ according to BGI and $69.15 \%$ according to Invitae Laboratories [25,41].

Other trisomies can be detected by chance with the low genome coverage version. Of the aneuploidies found in our study group, only trisomy 14 falls into this group, noting that this abnormality is not part of the standard aneuploidies expected to be identified, but it is an abnormality that can be additionally detected by NIFTY [44]. In addition to the standard aneuploidies, in one case, a high-risk for trisomy 14 and for Xp deletion has been found. The 41-year-old pregnant woman had a positive medical history: a trisomy 21 pregnancy resulted in a stillbirth. The case was special because, after amniocentesis followed by QF-PCR, aCGH, and fetal karyotyping, trisomy 14 was ruled out; this was a false-positive result. The deletion of the short arm of the $\mathrm{X}$ chromosome was confirmed, and a translocation between chromosome 14 and the $\mathrm{Xq}$ arm was identified. The fetus had numerous ultrasound abnormalities, and termination of pregnancy for medical reasons was decided. Rare autosomal trisomies are important but not so rare. Scott et al. found that they are often associated with poor obstetric outcomes [45]. Preimplantation testing was performed in two pregnancies (2/7) obtained by IVF (outside Romania). NIPT was also carried out (NIFTY in one pregnancy and NIPS in the other one), confirming the sex of the fetus and the absence of aneuploidies.

\subsection{Twins}

Twin cases are particular in many ways. First, NIPT analysis can only evaluate the risk of aneuploidy and not of microdeletions. Our study included 2 pregnant women (30 and 36 years old) without other indications besides NIPT increased risk for trisomy 21 and trisomy 18, respectively. In both cases the twins were of different genders. In each case, two amniocenteses were performed followed by QF-PCR and fetal karyotyping and in both cases, one of the twins was confirmed with a trisomy (one male fetus with trisomy 21 and in the other pregnancy one female fetus with trisomy 18). In both cases, the parents decided to stop the pregnancy. Another peculiarity of twin pregnancies is related to the vanishing twin, whose sex can cause false-positive results for fetal gender. As the pregnancy progresses, the ultrasound sex is observed, and if there are discordances, a disorder of sex development must be considered. In these cases, genetic counseling and detailed anamnesis are especially useful and can further guide pregnancy management. BGI recommends waiting 8 weeks after the disappearance of a twin before taking the NIPT test; it is considered that the FF of the vanished twin has decreased considerably during these weeks and no longer influences the result. However, this is impossible to achieve when the pregnant woman presents to the first obstetric consultation too late for confirmation of pregnancy, a few weeks after the signs of a twin pregnancy disappears. Therefore, we encourage pregnant women to have their first obstetric consultation as soon as possible. A recent study has found that trisomy 21,18 , and 13 , as well as $\mathrm{X}$ chromosome aneuploidies, were accurately detected by NIPT in twin pregnancies. As in our study, the aneuploidies mostly occurred in only one twin. The authors agreed that NIPT could be used as routine prenatal screening in twin pregnancies [46]. If there are more than two fetuses, the risk of a false-positive and negative results increases. In their study, Hartwig et al. reported four false negative aneuploidy cases, of which two were explained by a vanishing twin. The sensitivity and specificity, when no-calls and vanished twins were excluded, were $100 \%$ and $99.5 \%$ for trisomy $21,91 \%$ and $99.2 \%$ for trisomy 18 , and $100 \%$ and $99.6 \%$ for trisomy 13 [47]. 
Many factors, both maternal (such as maternal blood transfusion, surgery, immunotherapy, neoplasm, or mosaicism) and pregnancy-related (vanishing twin, fetal demise, confined placental mosaicism, true fetal mosaicism, uniparental disomy, and polyploidy), can affect the results. In our study, the pregnant women denied such medical conditions. Regarding pregnancy-related factors, fetal ultrasonography did not reveal the presence of a vanishing twin. The other above-mentioned chromosomal abnormalities were not identified with invasive techniques. Fetal demise during weeks 20-30 of gestation was registered in 2 cases, both having NIPT low-risk results, and the causes were not established. We also gathered information about births and offspring, revealing that a female newborn from a twin pregnancy was diagnosed with Treacher Collins syndrome after birth. All other newborns were considered healthy at birth without any suspicion of chromosomal syndromes.

\subsection{Microdeletion/Microduplication Syndromes}

Microdeletion and microduplication syndromes are caused by CNVs and are relatively rare disorders [48]. It is estimated that they account for $1-2 \%$ of all newborn congenital anomalies and the most common is 22q11.2 deletion syndrome [49].

NIPT test can detect specific loci relevant to microdeletion/microduplication syndromes according to OMIM and Decipher databases. The risk of false-positive/negative results in these cases can be increased compared to common trisomies. Due to the low prevalence of these microdeletion syndromes and the limited performance data for these disorders, it is not possible to calculate a precise and accurate PPV.

Our study included cases analyzed during 2014 using the NIFTY test. At that time, three aneuploidies (for chromosomes 13,18, 21) and three microdeletions (1p36 deletion syndrome, $5 \mathrm{p}$ Cri du Chat syndrome, 2q33.1 deletion syndrome) could be tested. During 2015, the test was improved, enabling identification of six aneuploidies (chromosomes 9, 16, 22 were added) and eight microdeletion syndromes (5p, 1p36, Van der Woude 1q32.2, 2q33.1, 16p12.2, DiGeorge 2, Jacobsen 11q23, Prader-Willi/Angelman). In 2017 the number of microdeletions that could be tested increased to 63, and in 2018 the test changed its name to Nifty-pro, and the number of microdeletions increased to 84 .

In our study, 5 out of 6 cases identified as having a high-risk of microdeletions, were ruled out; therefore our PPV was only $16.66 \%$. One of our cases had a high-risk of Xp microdeletion, of $54.27 \mathrm{Mb}$; after aCGH was performed, it has been confirmed, but having a larger size, $61.88 \mathrm{Mb}$. FF, in this case, was $15.64 \%$, the highest in the group at risk of microdeletions.

The other microdeletions, which were not confirmed, were smaller, their sizes ranging from $5.06 \mathrm{Mb}$ to $22.57 \mathrm{Mb}$. The deletions identified in these 5 cases were: del (10q25), del $(15 q)$, del (20q), del 1p36 and del(22q11.2) microdeletion syndrome. All five were ruled out following direct analysis of fetal cells by aCGH. The gestational age was variable, ranging between 11-16 weeks.

Detection of microdeletions can be performed by the BGI laboratory through low coverage whole genome sequencing using NGS technology and a bioinformatics algorithm, which allows the identification of 84 deletions and duplications. Internal analysis of BGI showed a sensitivity exceeding 90\% (cfDNA9.5\%) in selected del/dup syndromes with abnormal size over $3 \mathrm{Mb}$.

The maternal presence of CNVs, as recently reported in two cases, could explain why the results yielded by NIPT are not confirmed by invasive methods [48]. Microdeletions can occur de novo in most cases but can also be inherited if a parent has a balanced translocation. Results should always be reviewed with a qualified healthcare professional. High-risk results must be followed by confirmatory diagnostic testing.

The PPV and NPV reported scores do not consider additional clinical information such as previous screening results, positive family history, or abnormal ultrasound findings. It is not possible to calculate a precise and accurate PPV for sex chromosome aneuploidies due to their uncertain prevalence and the limited performance data for these disorders. Moreover, 
due to the low prevalence of microdeletion syndromes and the limited performance data for these disorders, it is not possible to calculate a precise and accurate PPV as well. The Netherlands launched a study on NIPT as a first-tier test offered to all pregnant women. This study confirmed that genome-wide NIPT is a reliable and robust screening test. PPVs found by the authors were $96 \%$ for trisomy $21,98 \%$ for trisomy 18 , and $53 \%$ for trisomy 13 and were higher than expected [50].

Another study that examined over 8000 single pregnancies with NIPT reported that PPVs for trisomy 13, 18, 21 and sex chromosome aneuploidy were $14.28 \%, 60 \%, 80 \%$, and $45.83 \%$, respectively. At the same time, they have found $0.63 \%$ positive cases for chromosomal microdeletions or microduplications, but only $36.11 \%$ of them were truepositive cases. They concluded that NIPT had the highest accuracy for trisomy 21 detection, while accuracy was low for chromosomal microdeletion and microduplications [51].

\subsection{Pre-Eclampsia}

In one case, with low-risk NIPT, the fetal death was caused by pre-eclampsia, with onset at 25 weeks. Determining the genetic risk of hypertension before pregnancy is part of high-quality medical care because a proper low-salt diet can increase the chance that the pregnancy will progress to near term and give birth to a healthy baby. Various pathophysiological mechanisms have been involved in the onset of pre-eclampsia [52,53]. A comprehensive literature search of several databases conducted to identify relevant studies that evaluated cell-free fetal DNA levels in pregnant women before the clinical onset of pre-eclampsia revealed that cell-free fetal DNA quantification is a marker predicting the development of pre-eclampsia. The authors concluded that it could probably only be used from the beginning of the second trimester; otherwise, the detection rate is too low or not significant [54]. Several studies suggested that a low FF on NIPT might be correlated with future hypertensive disease [55-57], while Bender et al. found that FF at 10 to 20 weeks of pregnancy has not been associated with the development of gestational hypertension [58]. Even if there is a significant association between FF and first-trimester markers for adverse pregnancy outcomes, further research is needed to establish if it could act as an independent first-trimester marker in an algorithm for screening for pre-eclampsia [59].

\subsection{Genetic Counseling}

NIPT is an advanced screening test, incorporated into clinical practice in the context of genetic counseling. The genetic counselor should highlight that NIPT is a screening test, but the detection rate is superior to that of maternal serum screening, which has a misdiagnosis rate of 5 to $50 \%$ [8]. NIPT results may indicate an increased risk for specific conditions. The healthcare provider will further interpret the NIPT results in the context of the patient's clinical data and family history and will recommend genetic counseling and additional testing when appropriate. Diagnostic testing should be performed to confirm a positive result [60].

In clinical practice, one patient requires several genetic counseling sessions [61]. This series of investigations with genetic counseling at each step requires a great involvement of the geneticist who coordinates the sequence of these tests and explains the results, sometimes inconsistent with the initial NIPT results.

In our study, four pregnant women $(1.05 \%)$ were carriers of an X-linked recessive gene, and the analysis was performed for result-oriented care, focusing on the fetal sex. In all cases, the fetal gender was identified as female and had a low-risk NIPT. Pan et al. developed a fetal sex determination method based on maternal plasma sequencing and assessed its potential use in X-linked disorders counseling, concluding that high accuracy of non-invasive fetal sex determination can be achieved [62].

Several other cases had a history of single-gene diseases in the family, and even if NIPT could not detect a risk for these conditions, further explanations were needed, and amniocentesis was recommended. In two cases with advanced maternal age, after a lowrisk NIPT result, the management of the pregnancy was oriented towards amniocentesis 
to test the fetus for known mutations that could have been inherited from the carrier's parents [63-66].

NIPT newer technologies have already expanded prenatal screening beyond common autosomal aneuploidies to smaller chromosomal abnormalities. Other tests for single-gene disorders are currently developed, but their validation is important. Parents should be provided with appropriate genetic counseling by a qualified professional $[67,68]$.

\subsection{Strengths and Limitations}

Any result that indicates a high-risk NIPT should be followed by an invasive method, but not all pregnant women accept it easily. In such cases, it is beneficial to explain that the invasive method remains the "gold standard" in diagnosing genetic diseases and clarifying diagnostic controversies. On the other hand, in cases with ultrasound abnormalities and a low-risk NIPT result, the area of investigations was widened in order to identify the cause and establish the management of the pregnancy.

Although one limitation of the study is the small sample size, the study is valuable because it is the first to present NIPT issues in a group of patients in Romania. We hope that sharing our experience will be useful to specialists working in this field. Another study limitation is related to the lower number of microdeletions that could be initially detected and which increased over time. Not all patients were tested for the same number of microdeletions. The study also reflects the progression over time of NIPT's scientific knowledge and investigative power.

\section{Conclusions}

This is the first study in our country reporting the NIPT results from a series of 380 cases (Caucasians from Eastern Europe). In our study, confirmation rate was higher for autosomal aneuploidies compared to sex chromosome aneuploidies and microdeletions. All cases at risk for trisomy 21 were confirmed. A trisomy 13 with a false-negative NIPT result was identified via invasive prenatal diagnosis. Only one large fetal microdeletion detected by NIPT has been confirmed. False-positive NIPT results, which were not confirmed by invasive methods, led to the decision to continue the pregnancy, bringing relief to pregnant women. A gestational age of up to 22 weeks had no influence on fetal fraction. We did not find significant differences in fetal fraction across the high and low-risk groups. The main limitation of the study is the small number of patients included. NIPT can be used as a screening method for all pregnancies, but in high-risk cases, an invasive confirmation test is strongly recommended, and no definitive measure of pregnancy termination should be taken without a result obtained by an invasive method.

Supplementary Materials: The following are available online at https:/ / www.mdpi.com/article/10 $.3390 /$ medicina58010079/s1, Table S1: Combinations of indications and the results of the study.

Author Contributions: Conceptualization, C.G. and D.S.; methodology, E.V.G.; software, A.R.; formal analysis, M.A.V.; investigation, A.T., C.F. and G.F.; resources, L.C.; data curation, M.G. and C.C.; writing-original draft preparation, C.G. and D.S.; writing-review and editing, I.M. who was also a correspondence author; visualization, D.S.; supervision, C.G. All authors have read and agreed to the published version of the manuscript.

Funding: This research received no external funding.

Institutional Review Board Statement: The study was conducted according to the guidelines of the Declaration of Helsinki, and approved by the Institutional Review Board (or Ethics Committee) of Emergency Clinical Municipal Hospital Timisoara, Romania (protocol code No. 6-2846 from 8 July 2020).

Informed Consent Statement: Informed consent was obtained from all subjects involved in the study. Written informed consent has been obtained from the patient(s) to publish this paper.

Acknowledgments: We express our gratitude to all patients who participated in this study. The authors would like to thank to the collaborators from the partner laboratories: BGI Laboratory and Invitae.

Conflicts of Interest: The authors declare no conflict of interest. 


\section{References}

1. Yu, D.; Zhang, K.; Han, M.; Wei, P.; Ying, C.; Yunfeng, W.; Hongyan, J.; Ling, D.; Qiying, Z.; Xiaojie, S.; et al. Noninvasive prenatal testing for fetal subchromosomal copy number variations and chromosomal aneuploidy by low-pass whole-genome sequencing. Mol. Genet. Genom. Med. 2019, 7, e674. [CrossRef] [PubMed]

2. Benn, P.; Cuckle, H.; Pergament, E. Non-invasive prenatal testing for aneuploidy: Current status and future prospects. Ultrasound Obstet. Gynecol. 2013, 42, 15-33. [CrossRef] [PubMed]

3. Minear, M.A.; Lewis, C.; Pradhan, S.; Chandrasekharan, S. Global perspectives on clinical adoption of NIPT. Prenat. Diagn. 2015, 35, 959-967. [CrossRef] [PubMed]

4. $\quad$ Lo, Y.M.D.; Corbetta, N.; Chamberlain, P.F.; Rai, V.; Sargent, I.L.; Redman, C.W.; Wainscoat, J.S. Presence of fetal DNA in maternal plasma and serum. Lancet 1997, 350, 485-487. [CrossRef]

5. Wang, Y.; Li, S.; Wang, W.; Dong, Y.; Zhang, M.; Wang, X.; Yin, C. Cell-free DNA screening for sex chromosome aneuploidies by non-invasive prenatal testing in maternal plasma. Mol. Cytogenet. 2020, 13, 1-8. [CrossRef]

6. Russo, M.L.; Blakemore, K.J. A historical and practical review of first trimester aneuploidy screening. Semin. Fetal Neonatal Med. 2014, 19, 183-187. [CrossRef]

7. Health Quality Ontario. Noninvasive Prenatal Testing for Trisomies 21, 18, and 13, Sex Chromosome Aneuploidies, and Mi-crodeletions: A Health Technology Assessment. Ont. Health Technol. Assess. Ser. 2019, 19, 1-166.

8. Nicolaides, K. Screening for fetal aneuploidies at 11 to 13 weeks. Prenat. Diagn. 2011, 31, 7-15. [CrossRef]

9. Gorduza, E.V.; Socolov, D.G.; Socolov, R.V. Prenatal Biochemical and Ultrasound Markers in Chromosomal Anomalies. In Congenital Anomalies-From the Embryo to the Neonate, 1st ed.; IntechOpen: Zagreb, Croatia, 2018; Volume 1, pp. 365-396. [CrossRef]

10. Dey, M.; Sharma, S.; Aggarwal, S. Prenatal screening methods for aneuploidies. N. Am. J. Med. Sci. 2013, 5, 182-190. [CrossRef]

11. Lu, X.; Wang, C.; Sun, Y.; Tang, J.; Tong, K.; Zhu, J. Noninvasive prenatal testing for assessing foetal sex chromosome aneu-ploidy: A retrospective study of 45,773 cases. Mol. Cytogenet. 2021, 14, 1. [CrossRef]

12. Zarrei, M.; MacDonald, J.; Merico, D.; Scherer, S. A copy number variation map of the human genome. Nat. Rev. Genet. 2015, 16, 172-183. [CrossRef] [PubMed]

13. Popescu, R.; Grămescu, M.; Caba, L.; Pânzaru, M.-C.; Butnariu, L.; Braha, E.; Popa, S.; Rusu, C.; Cardos, G.; Zeleniuc, M.; et al. A Case of Inherited $\mathrm{t}(4 ; 10)(\mathrm{q} 26 ; \mathrm{q} 26.2)$ Chromosomal Translocation Elucidated by Multiple Chromosomal and Molecular Analyses. Case Report and Review of the Literature. Genes 2021, 12, 1957. [CrossRef] [PubMed]

14. Gug, C.; Stoicanescu, D.; Mozos, I.; Nussbaum, L.; Cevei, M.; Stambouli, D.; Pavel, A.G.; Doros, G. De novo 8p21.3 $\rightarrow$ p23.3 Duplication With $\mathrm{t}(4 ; 8)$ (q35;p21.3) Translocation Associated With Mental Retardation, Autism Spectrum Disorder, and Con-genital Heart Defects: Case Report With Literature Review. Front. Pediatr. 2020, 8, 375. [CrossRef] [PubMed]

15. LaLonde, E.; Rentas, S.; Lin, F.; Dulik, M.C.; Skraban, C.M.; Spinner, N.B. Genomic Diagnosis for Pediatric Disorders: Revolution and Evolution. Front. Pediatr. 2020, 8, 373. [CrossRef] [PubMed]

16. Gug, C.; Huțanu, D.; Vaida, M.; Doroş, G.; Popa, C.; Stroescu, R.; Furău, G.; Furau, C.; Grigorita, L.; Mozos, I. De novo un-balanced translocation $\mathrm{t}(15 ; 22)(\mathrm{q} 26.2 ; \mathrm{q} 12)$ with velo-cardio-facial syndrome: A case report and review of the literature. Exp. Ther. Med. 2018, 16, 3589-3595. [CrossRef]

17. Goldenberg, P. An Update on Common Chromosome Microdeletion and Microduplication Syndromes. Pediatr. Ann. 2018, 47, e198-e203. [CrossRef]

18. Wapner, R.; Babiarz, J.E.; Levy, B.; Stosic, M.; Zimmermann, B.; Sigurjonsson, S.; Wayham, N.; Ryan, A.; Banjevic, M.; Lacroute, P.; et al. Expanding the scope of noninvasive prenatal testing: Detection of fetal microdeletion syndromes. Am. J. Obstet. Gynecol. 2015, 212, 332.e1-332.e9. [CrossRef]

19. Liu, H.; Gao, Y.; Hu, Z.; Lin, L.; Yin, X.; Wang, J.; Chen, D.; Chen, F.; Jiang, H.; Ren, J.; et al. Performance Evaluation of NIPT in Detection of Chromosomal Copy Number Variants Using Low-Coverage Whole-Genome Sequencing of Plasma DNA. PLoS ONE 2016, 11, e0159233. [CrossRef]

20. Sun, X.; Lu, J.; Ma, X. An efficient method for noninvasive prenatal diagnosis of fetal trisomy 13, trisomy 18, and trisomy 21. PLoS ONE 2019, 14, e0215368. [CrossRef]

21. Samura, O. Update on noninvasive prenatal testing: A review based on current worldwide research. J. Obstet. Gynaecol. Res. 2020, 46, 1246-1254. [CrossRef]

22. Koumbaris, G.; Achilleos, A.; Nicolaou, M.; Loizides, C.; Tsangaras, K.; Kypri, E.; Mina, P.; Sismani, C.; Velissariou, V.; Christopoulou, G.; et al. Targeted capture enrichment followed by NGS: Development and validation of a single comprehensive NIPT for chromosomal aneuploidies, microdeletion syndromes and monogenic diseases. Mol. Cytogenet. 2019, 12, 48. [CrossRef]

23. Gug, C.; Chiriac, V.D.; Catu, D.; Budau, G.; Costa, S.D.; Navolan, D.B. Prenatal Cytogenetic Diagnosis in Timisoara: 1 Year Experience. Timis. Med. J. 2003, 53, 113-117.

24. Yao, H.; Jiang, F.; Hu, H.; Gao, Y.; Zhu, Z.; Zhang, H.; Wang, Y.; Guo, Y.; Liu, L.; Yuan, Y.; et al. Detection of fetal sex chro-mosome aneuploidy by massively parallel sequencing of maternal plasma DNA: Initial experience in a Chinese hospital. Ul-trasound Obstet. Gynecol. 2014, 44, 17-24. [CrossRef]

25. Bianchi, D.W.; Platt, L.D.; Goldberg, J.D.; Abuhamad, A.Z.; Sehnert, A.J.; Rava, R.P. Genome-Wide Fetal Aneuploidy Detection by Maternal Plasma DNA Sequencing. Obstet. Gynecol. 2012, 119, 890-901. [CrossRef]

26. Bianchi, D.W.; Chiu, R.W.K. Sequencing of Circulating Cell-free DNA during Pregnancy. N. Engl. J. Med. 2018, 379, 464-473. [CrossRef] 
27. Taneja, P.A.; Prosen, T.L.; De Feo, E.; Kruglyak, K.M.; Halks-Miller, M.; Curnow, K.J.; Bhatt, S. Fetal aneuploidy screening with cell-free DNA in late gestation. J. Matern. Neonatal Med. 2017, 30, 338-342. [CrossRef]

28. Hestand, M.S.; Bessem, M.; Van Rijn, P.; De Menezes, R.X.; Sie, D.; Bakker, I.; Boon, E.M.J.; Sistermans, E.A.; Weiss, M.M. Fetal fraction evaluation in non-invasive prenatal screening (NIPS). Eur. J. Hum. Genet. 2018, 27, 198-202. [CrossRef] [PubMed]

29. Guo, F.; Yang, J.; Huang, Y.; Qi, Y.; Hou, Y.; Peng, H.; Wang, D.; Wang, Y.; Luo, X.; Li, Y.; et al. Association between fetal fraction at the second trimester and subsequent spontaneous preterm birth. Prenat. Diagn. 2019, 39, 1191-1197. [CrossRef]

30. Hou, Y.; Yang, J.; Qi, Y.; Guo, F.; Peng, H.; Wang, D.; Wang, Y.; Luo, X.; Li, Y.; Yin, A. Factors affecting cell-free DNA fetal fraction: Statistical analysis of 13,661 maternal plasmas for non-invasive prenatal screening. Hum. Genom. 2019, 13, 1-8. [CrossRef] [PubMed]

31. Hudecova, I.; Sahota, D.; Heung, M.M.S.; Jin, Y.; Lee, W.S.; Leung, T.Y.; Lo, Y.M.D.; Chiu, R.W. Maternal Plasma Fetal DNA Fractions in Pregnancies with Low and High Risks for Fetal Chromosomal Aneuploidies. PLoS ONE 2014, 9, e88484. [CrossRef] [PubMed]

32. Ashoor, G.; Poon, L.C.; Syngelaki, A.; Mosimann, B.; Nicolaides, K.H. Fetal Fraction in Maternal Plasma Cell-Free DNA at 11-13 Weeks' Gestation: Effect of Maternal and Fetal Factors. Fetal Diagn. Ther. 2012, 31, 237-243. [CrossRef] [PubMed]

33. Palomaki, G.E.; Kloza, E.M.; Lambert-Messerlian, G.M.; van den Boom, D.; Ehrich, M.; Deciu, C.; Bombard, A.T.; Haddow, J.E. Circulating cell free DNA testing: Are some test failures informative? Prenat. Diagn. 2015, 35, 289-293. [CrossRef] [PubMed]

34. McKanna, T.; Ryan, A.; Krinshpun, S.; Kareht, S.; Marchand, K.; Grabarits, C.; Ali, M.; McElheny, A.; Gardiner, K.; Lechien, K.; et al. Fetal fraction-based risk algorithm for non-invasive prenatal testing: Screening for trisomies 13 and 18 and triploidy in women with low cell-free fetal DNA. Ultrasound Obstet. Gynecol. 2019, 53, 73-79. [CrossRef]

35. Gug, C.; Rațiu, A.; Navolan, D.; DrĂgan, I.; Groza, I.-M.; Păpurică, M.; Vaida, M.-A.; Mozoș, I.; Jurcă, M.C. Incidence and Spectrum of Chromosome Abnormalities in Miscarriage Samples: A Retrospective Study of 330 Cases. Cytogenet. Genome Res. 2019, 158, 171-183. [CrossRef] [PubMed]

36. Gug, C.; Burada, F.; Ioana, M.; Riza, A.L.; Moldovan, M.; Mozoș, I.; Rațiu, A.; Martiniuc, V.; Gorduza, E.V. Polyploidy in First and Second Trimester Pregnancies in Romania-A Retrospective Study. Clin Lab. 2020, 66, 517-527. [CrossRef]

37. Chen, E.Z.; Chiu, R.W.K.; Sun, H.; Akolekar, R.; Chan, K.C.A.; Leung, T.Y.; Jiang, P.; Zheng, Y.W.L.; Lun, F.M.F.; Chan, L.Y.S.; et al. Noninvasive Prenatal Diagnosis of Fetal Trisomy 18 and Trisomy 13 by Maternal Plasma DNA Sequencing. PLoS ONE 2011, 6, e21791. [CrossRef]

38. Lo, Y.M.D.; Chan, K.C.A.; Sun, H.; Chen, E.Z.; Jiang, P.; Lun, F.M.F.; Zheng, Y.W.; Leung, T.Y.; Lau, T.K.; Cantor, C.R.; et al. Maternal Plasma DNA Sequencing Reveals the Genome-Wide Genetic and Mutational Profile of the Fetus. Sci. Transl. Med. 2010, 2, 61ra91. [CrossRef]

39. Yamada, T.; Sekizawa, A.; Fujii, Y.; Hirose, T.; Samura, O.; Suzumori, N.; Miura, K.; Sawai, H.; Hirahara, F.; Murotsuki, J. Maternal age-specific risk for trisomy 21 based on the clinical performance of NIPT and empirically derived NIPT age-specific positive and negative predictive values in Japan. J. Hum. Genet. 2018, 63, 1035-1040. [CrossRef]

40. Zhang, H.; Gao, Y.; Jiang, F.; Fu, M.; Yuan, Y.; Guo, Y.; Zhu, Z.; Lin, M.; Liu, Q.; Tian, Z.; et al. Non-invasive prenatal testing for trisomies 21, 18 and 13: Clinical experience from 146958 pregnancies. Ultrasound Obstet. Gynecol. 2015, 45, 530-538. [CrossRef]

41. Jiang, F.; Ren, J.; Chen, F.; Zhou, Y.; Xie, J.; Dan, S.; Su, Y.; Xie, J.; Yin, B.; Su, W.; et al. Noninvasive Fetal Trisomy (NIFTY) test: An advanced noninvasive prenatal diagnosis methodology for fetal autosomal and sex chromosomal aneuploidies. BMC Med Genom. 2012, 5, 57. [CrossRef]

42. Vaida, M.A.; Streian, C.G.; Gug, C.; Damen, N.S.; Jianu, A.M.; Grigoriță, A.; Grigoriță, L. Morphological Study of Fossa Ovalis in Formalin-Fixed Human Hearts and Its Clinical Importance. Medicina 2021, 57, 1254. [CrossRef] [PubMed]

43. Yu, S.C.Y.; Chan, K.C.A.; Zheng, Y.W.L.; Jiang, P.; Liao, G.J.W.; Sun, H.; Akolekar, R.; Leung, T.Y.; Go, A.T.J.I.; van Vugt, J.M.G.; et al. Size-based molecular diagnostics using plasma DNA for noninvasive prenatal testing. Proc. Natl. Acad. Sci. USA 2014, 111, 8583-8588. [CrossRef] [PubMed]

44. Kleinfinger, P.; Lohmann, L.; Luscan, A.; Trost, D.; Bidat, L.; Debarge, V.; Castaigne, V.; Senat, M.-V.; Brechard, M.-P.; Guilbaud, L.; et al. Strategy for Use of Genome-Wide Non-Invasive Prenatal Testing for Rare Autosomal Aneuploidies and Unbalanced Structural Chromosomal Anomalies. J. Clin. Med. 2020, 9, 2466. [CrossRef] [PubMed]

45. Scott, F.; Bonifacio, M.; Sandow, R.; Ellis, K.; Smet, M.E.; McLennan, A. Rare autosomal trisomies: Important and not so rare. Prenat Diagn. 2018, 38, 765-771. [CrossRef]

46. Yu, W.; Lv, Y.; Yin, S.; Liu, H.; Li, X.; Liang, B.; Kong, L.; Liu, C. Screening of fetal chromosomal aneuploidy diseases using noninvasive prenatal testing in twin pregnancies. Expert Rev. Mol. Diagn. 2019, 19, 189-196. [CrossRef]

47. Hartwig, T.S.; Ambye, L.; Werge, L.; Weiergang, M.P.; Nørgaard, P.; Sørensen, S.; Jørgensen, F.S. Non-Invasive Prenatal Testing (NIPT) in pregnancies with trisomy 21, 18 and 13 performed in a public setting-Factors of importance for correct in-terpretation of results. Eur. J. Obstet. Gynecol. Reprod. Biol. 2018, 226, 35-39. [CrossRef]

48. Qi, Y.; Yang, J.; Hou, Y.; Hu, R.; Wang, D.; Peng, H.; Yin, A. Potential influence of parental copy number variations on non-invasive prenatal testing (NIPT): Two case reports. Mol. Cytogenet. 2020, 13, 18. [CrossRef]

49. Wapner, R.J.; Martin, C.L.; Levy, B.; Ballif, B.C.; Eng, C.M.; Zachary, J.M.; Savage, M.; Platt, L.D.; Saltzman, D.; Grobman, W.A.; et al. Chromosomal microarray versus karyotyping for prenatal diagnosis. N. Engl. J Med. 2012, 367, 2175-2184. [CrossRef] 
50. van der Meij, K.R.; Sistermans, E.A.; Macville, M.V.; Stevens, S.J.; Bax, C.J.; Bekker, M.N.; Bilardo, C.M.; Boon, E.M.; Boter, M.; Diderich, K.E.; et al. TRIDENT-2: National Implementation of Genome-wide Non-invasive Prenatal Testing as a First-Tier Screening Test in the Netherlands. Am. J. Hum. Genet. 2019, 105, 1091-1101. [CrossRef]

51. Hu, H.; Wang, L.; Wu, J.; Zhou, P.; Fu, J.; Sun, J.; Cai, W.; Liu, H.; Yang, Y. Noninvasive prenatal testing for chromosome aneuploidies and subchromosomal microdeletions/microduplications in a cohort of 8141 single pregnancies. Hum. Genom. 2019, 13, 14. [CrossRef]

52. Mozos, I.; Jianu, D.; Gug, C.; Stoian, D. Links between High-Sensitivity C-Reactive Protein and Pulse Wave Analysis in MiddleAged Patients with Hypertension and High Normal Blood Pressure. Dis. Markers 2019, 2019, 2568069. [CrossRef]

53. Mozos, I.; Gug, C.; Mozos, C.; Stoian, D.; Pricop, M.; Jianu, D. Associations between Intrinsic Heart Rate, P Wave and QT Interval Durations and Pulse Wave Analysis in Patients with Hypertension and High Normal Blood Pressure. Int. J. Environ. Res. Public Health 2020, 17, 4350. [CrossRef]

54. Contro, E.; Bernabini, D.; Farina, A. Cell-Free Fetal DNA for the Prediction of Pre-Eclampsia at the First and Second Trimesters: A Systematic Review and Meta-Analysis. Mol. Diagn. Ther. 2017, 21, 125-135. [CrossRef]

55. Thurik, F.F.; Ruiter, M.L.-D.; Javadi, A.; Kwee, A.; Woortmeijer, H.; Page-Christiaens, G.C.M.L.; Franx, A.; Van Der Schoot, C.E.; Koster, M.P.H. Absolute first trimester cell-free DNA levels and their associations with adverse pregnancy outcomes. Prenat. Diagn. 2016, 36, 1104-1111. [CrossRef] [PubMed]

56. Suzumori, N.; Sekizawa, A.; Ebara, T.; Samura, O.; Sasaki, A.; Akaishi, R.; Wada, S.; Hamanoue, H.; Hirahara, F.; Izumi, H.; et al. Fetal cell-free DNA fraction in maternal plasma for the prediction of hypertensive disorders of pregnancy. Eur. J. Obstet. Gynecol. Reprod. Biol. 2018, 224, 165-169. [CrossRef] [PubMed]

57. Gerson, K.D.; Truong, S.; Haviland, M.J.; O’Brien, B.M.; Hacker, M.R.; Spiel, M.H. Low fetal fraction of cell-free DNA predicts placental dysfunction and hypertensive disease in pregnancy. Pregnancy Hypertens. 2019, 16, 148-153. [CrossRef]

58. Koelper, N.C.; Sammel, M.D.; Dugoff, L.; Bender, W.R. Association of Fetal Fraction of Cell-Free DNA and Hypertensive Disorders of Pregnancy. Am. J. Perinatol. 2018, 36, 311-316. [CrossRef]

59. Rolnik, D.L.; Costa, F.D.S.; Lee, T.J.; Schmid, M.; McLennan, A.C. Association Between Fetal Fraction on Cell-Free DNA Testing and First-Trimester Markers for Pre-eclampsia. Obstet. Gynecol. Surv. 2019, 74, 265-266. [CrossRef]

60. Buchanan, A.; Sachs, A.; Toler, T.; Tsipis, J. NIPT: Current utilization and implications for the future of prenatal genetic counseling. Prenat. Diagn. 2014, 34, 850-857. [CrossRef] [PubMed]

61. Wax, J.R.; Cartin, A.; Chard, R.; Lucas, F.L.; Pinette, M.G. Noninvasive prenatal testing: Impact on genetic counseling, invasive prenatal diagnosis, and trisomy 21 detection. J. Clin. Ultrasound 2015, 43, 1-6. [CrossRef]

62. Pan, X.; Zhang, C.; Li, X.; Chen, S.; Huijuan, G.; Zhang, Y.; Chen, F.; Jiang, H.; Jiang, F.; Zhang, H.; et al. Noninvasive fetal sex determination by maternal plasma sequencing and application in X-linked disorder counseling. J. Matern Fetal Neonatal Med. 2014, 27, 1829-1833. [CrossRef] [PubMed]

63. Belengeanu, V.; Rozsnyai, K.; Gug, C.; Bănăţeanu, M.; Farcaş, S.; Belengeanu, A. Ambras syndrome: Report on two affected siblings with no prior family history. Clin. Dysmorphol. 2004, 13, 265-267. [CrossRef] [PubMed]

64. Gug, C.; Mihaescu, A.; Mozos, I. Two mutations in the thiazide-sensitive $\mathrm{NaCl}$ co-transporter gene in a Romanian Gitelman syndrome patient: Case report. Ther. Clin. Risk Manag. 2018, 14, 149-155. [CrossRef] [PubMed]

65. Gug, C.; Gorduza, E.V.; Lăcătuşu, A.; Vaida, M.A.; Bîrsăşteanu, F.; Puiu, M.; Stoicănescu, D. CHARGE syndrome associated with de novo (I1460Rfs*15) frameshift mutation of CHD7 gene in a patient with arteria lusoria and horseshoe kidney. Exp. Ther. Med. 2020, 20, 479-485. [CrossRef]

66. Gug, C.; Caba, L.; Mozos, I.; Stoian, D.; Atasie, D.; Gug, M.; Gorduza, E.V. Rare splicing mutation in COL1A1 gene identified by whole exomes sequencing in a patient with osteogenesis imperfecta type I followed by prenatal diagnosis: A case report and review of the literature. Gene 2020, 741, 144565. [CrossRef]

67. Shaw, J.; Scotchman, E.; Chandler, N.; Chitty, L. Non-invasive prenatal testing for aneuploidy, copy number variants and single gene disorders. Reproduction 2020, 160, A1-A11. [CrossRef]

68. Belengeanu, V.; Stoicanescu, D.; Stoian, M.; Andreescu, N.; Budisan, C. Ichthyosis congenita, harlequin fetus type: A case report. Adv. Med. Sci. 2009, 54, 113-115. [CrossRef] 